\title{
Características físico-químicas de grãos de milho atacados por Sitophilus zeamais durante 0 armazenamento
}

\author{
Luidi E. G. Antunes ${ }^{1}$, Priscila C. Viebrant ${ }^{1}$, Roberto G ottardi ${ }^{1} \&$ Rafael G. D ionello ${ }^{1}$
}

\section{RESUMO}

O objetivo do trabalho foi avaliar os danos físicos e químicos causados por insetos adultos da espécie Sitophilus zeamais (M otschulsky) (Coleoptera: Curculionidae), criação própria sob condições controladas $\left(25 \pm 5{ }^{\circ} \mathrm{C}\right.$ e $60 \pm 10 \%$ UR), em grãos de milho híbrido (Zea mays L.) AS-32, oriundos de lavoura experimental, durante três períodos de armazenamento: 30,60 e 120 dias. 0 experimento ocorreu nas mesmas condições e foi constituído de quatro repetições de $600 \mathrm{~g}$ de grãos com 150 insetos para cada tratamento. As análises realizadas também com o produto "in natura" foram: umidade, perda de peso dos grãos, peso de 1000 grãos, tecnológica de defeitos, extrato etéreo, proteína bruta e variação populacional (emergência, mortalidade e sobrevivência dos insetos). No maior período avaliado (120 dias) ocorreram as maiores perdas de peso, presença de grãos carunchados, grau de umidade, variação populacional e menor peso de 1000 grãos e extrato etéreo. Pode-se concluir, com base nesses resultados, que quanto maior o período de contato dos insetos com os grãos maiores são os danos causados e os prejuízos para os produtores.

Palavras-chave: perda de peso, extrato etéreo, proteína, gorgulho-do-milho

\section{Physicochemical characteristics of corn damaged by Sitophilus zeamais during storage}

\begin{abstract}
The objective of present study was to evaluate the physical and chemical damage caused by the adult insects of the species Sitophilus zeamais (Motschulsky) (Coleoptera: Curculionidae), self creation under controlled conditions $\left(25 \pm 5{ }^{\circ} \mathrm{C}\right.$ and $\left.60 \pm 10 \% \mathrm{RH}\right)$ in grains of hybrid maize (Zea mays L.) AS-32, collected from an experimental farm for three storage periods: 30, 60 and 120 days. The experiment was conducted under the same conditions and consisted of four repetitions of $600 \mathrm{~g}$ of grain with 150 insects for each treatment. The analysis also performed with the product "in natura" were: moisture, weight loss of grain, 1000 grain weight, technological defects, ether extract, crude protein and population variation (emergence, mortality and survival of insects). The longest study period (120 days) showed the largest weight loss, presence of insect attacked grains, moisture content, population variation, and lower 1000 grain weight and lipids. O ne can conclude, based on these results, that the greater the contact period of insects with grains, the greater the damage and losses to farmers.
\end{abstract}

Key words: loss weight, ether extract, protein, maize weevil 


\section{INTRODUÇÃO}

Sitophilus zeamais (Motschulsky) (Coleoptera: Curculionidae), popularmente conhecido como gorgulho-domilho, é considerado uma das pragas mais importantes no setor de armazenamento de regiões tropicais (Faroni, 1992; Silveira et al., 2006). Suas principais características são: elevado potencial biótico, capacidade de atacar grãos tanto no campo quanto nas unidades armazenadoras e de sobreviver a grandes profundidades, na massa de grãos (Faroni, 1992).

De acordo com Schöller et al. (1997) as perdas de produtos armazenados podem atingir até $30 \%$ em alguns casos, das quais $10 \%$ causadas diretamente pelo ataque de pragas durante o armazenamento.

$\mathrm{O}$ ataque de insetos aos grãos armazenados, além das perdas quantitativas decorrentes da alimentação direta dos insetos, expressivas perdas qualitativas são acarretadas, como a diminuição do valor nutricional dos grãos e da qualidade fisiológica das sementes o que determina, consequentemente, a redução do valor de mercado ou até mesmo a condenação de lotes de sementes e/ou grãos (Anderson et al., 1990; Faroni, 1992; Caneppele et al., 2003).

Para processamento ou consumo, o valor do grão está diretamente relacionado com o nível de contaminação por insetos. As perdas quantitativas se referem às diminuições de peso e de volume, não mostrando adequadamente a degradação nutricional do produto (Silva et al., 1995).

A ração feita com grãos de milho que sofreram ataque de insetos, tende a diminuir o ganho de peso médio diário, o consumo médio diário, a conversão alimentar dos animais e a razão protéica líquida (Braga et al., 2003)

Segundo Bakker-Arkema (1994), para se avaliar a qualidade dos grãos consideram-se diversas propriedades qualitativas, como teor de água, massa específica, percentual de grãos quebrados, teor de impureza e matéria estranha, susceptibilidade à quebra, qualidade de moagem, conteúdo de proteínas, valor como ração, presença de insetos e fungos, e tipo de grão e ano de produção; entretanto, nem todas essas características qualitativas são consideradas apesar de serem de grande importância para compradores internacionais.

Em virtudes das perdas quantitativas que vêm sendo bastante estudadas por pesquisadores e dos poucos resultados com relação às perdas qualitativas, causadas por insetos na pós-colheita de grãos, o presente trabalho tem por objetivo analisar as perdas físicas e químicas em grãos de milho submetidos ao ataque de insetos adultos da espécie $S$. zeamais, assim como as variações populacionais ocorridas ao longo de três períodos de armazenamento: 30, 60 e 120 dias.

\section{Material e MÉTOdos}

O experimento foi realizado no Departamento de Fitossanidade da Faculdade de Agronomia/UFRGS, em sala climatizada $\left(25 \pm 5^{\circ} \mathrm{C}\right.$ e $60 \pm 10 \%$ UR). Os insetos utilizados foram provenientes de criação nas mesmas condições controladas, alimentados com grãos de milho (Zea mays L.), esses oriundos de lavoura experimental localizada na Estação Experimental Agronômica/UFRGS, situada na cidade de Eldorado do Sul, RS (km 146 da BR 290) e livres de tratamentos.

Para cada tempo de armazenamento foram utilizadas quatro repetições, cada uma com $600 \mathrm{~g}$ de milho híbrido variedade AS32 , que foram colocadas em frascos de vidro com capacidade de $500 \mathrm{~mL}$ fechado com tecido tipo voil.

Utilizaram-se 150 insetos não sexados e com idade entre 20 e 50 dias por repetição, oriundos de criação nas mesmas condições de temperatura e umidade, que foram colocados logo após a pesagem das amostras.

O experimento foi dividido em três etapas: após 30,60 e 120 dias de contato dos insetos com os grãos de milho, foram feitas avaliações físico-químicas; as análises também foram realizadas no produto "in natura", antes de se colocar os insetos. As análises realizadas foram:

\section{Umidade}

A determinação da umidade (\%b.u.) dos grãos foi realizada pelo método da estufa em temperatura de $105^{\circ} \mathrm{C}$, pelo período de 24 h (Brasil, 2009). Os resultados são expressos em \% de b.u.

\section{Perda de peso}

Com o uso de balança semianalítica (precisão de $0,01 \mathrm{~g}$ ) da marca GEHAKA pesaram-se os frascos de vidro e os grãos de milho necessários para cada repetiçãoe, ao final de cada período de armazenamento, novamente os grãos de milho híbrido foram pesados e o resíduo produzido pela população de insetos.

Visando à separação de resíduos, insetos e grãos, utilizaramse peneiras da marca EAGRI com malha contendo furos de 4,0 x $10 \mathrm{~mm}$ e 1,75 x $22 \mathrm{~mm}$ e se avaliaram, também, emergência, mortalidade e sobrevivência dos insetos, em cada intervalo de tempo.

\section{Peso de 1000 grãos}

O peso de 1000 grãos foi determinado com contagem de 8 repetições de 100 grãos e pesagem em balança analítica (Brasil, 2009). Os resultados são expressos em grama (g).

\section{Análise tecnológica de defeitos}

Os defeitos foram determinados pela metodologia oficial do Ministério da Agricultura (Brasil, 1996). Os resultados são expressos em percentagem.

\section{Proteína bruta}

O teor de proteína bruta foi obtido pelo método Kjeldahl, descrito pela AACC (2000). Os resultados são expressos em percentagem.

\section{Extrato etéreo}

A extração e a determinação do teor de extrato etéreo foram realizadas conforme o método AOCS (1996), com a utilização do aparelho Soxleht. Os resultados são expressos em percentagem.

Os valores dos resultados obtidos foram submetidos a análise de variância e suas médias discriminadas pelo teste de Tukey a $1 \%$. 


\section{RESULTADOS E DISCUSSÃO}

\section{Perda de peso dos grãos de milho}

Os resultados obtidos em relação à perda de peso dos grãos ao final de cada tempo de armazenamento, mostraram que ocorreram diferenças estatísticas entre as médias, ao longo do armazenamento, reduzindo significativamente o peso dos grãos ao longo dos 120 dias de armazenamento.

Em termos de percentagem e se tomando como $100 \%$ o peso inicial de cada tratamento, ocorreram diminuições de 2,2;3,0 e $17 \%$ para 30,60 e 120 dias, respectivamente (Tabela 1 ).

Tabela 1. Médias de perda de peso de grãos de milho híbrido armazenados com população de 150 insetos adultos de $\mathrm{S}$. zeamais em três períodos diferentes: 30,60 e 120 dias

\begin{tabular}{lccc}
\hline & \multicolumn{3}{c}{ Período de armazenamento (dias) } \\
\cline { 2 - 4 } & $\mathbf{3 0}$ & $\mathbf{6 0}$ & $\mathbf{1 2 0}$ \\
Peso inicial $(\mathrm{g})$ & 600,00 & 600,00 & 600,00 \\
Peso final $(\mathrm{g})$ & $587,07 \mathrm{a}$ & $559,03 \mathrm{~b}$ & $500,05 \mathrm{c}$ \\
Perdas (\%) & $2,20 \mathrm{c}$ & $3,00 \mathrm{~b}$ & $17,00 \mathrm{a}$ \\
\hline
\end{tabular}

Médias seguidas de mesma letra na coluna não diferem estatisticamente pelo teste de Tukey a 1\%

Considerando uma tonelada, essas perdas representariam 22,30 e $170 \mathrm{~kg}$ para 30, 60 e 120 dias, respectivamente. Como o milhoé vendido em sacos de $60 \mathrm{~kg}$, perdem-se aproximadamente 0,$37 ; 0,5 ; 2,83$ sacos nos três períodos respectivamente.

Esses dados se assemelham aos de Caneppele et al. (2003) que, estudando a correlação entre o nível de infestação de $S$. zeamais e a qualidade de armazenamento de grãos de milho, constataram o aumento de perda de peso desses grãos, conforme foram aumentados o tempo e o número de insetos em contato com os grãos de milho.

Esses autores concluem que uma perda média de massa seca de $0,36 \%$ por dia corresponde a um consumo de $0,0001 \%$ para cada inseto por mês, após 150 dias de armazenamento. Os autores observaram perdas de peso de $15,18 \%$, no período de 120 dias, quando utilizaram 50 insetos na infestação inicial.

Santos et al. (2002) observaram danos econômicos em grãos de milho causados por insetos, uma redução de peso de $21 \%$ aos 90 dias de armazenamento, quando utilizaram 300 insetos adultos de $S$. zeamais em 1,5 kg de trigo, de acordo com Massaro Júnior et al. (2005) que, estudando inibidores de amilase em híbridos de milho na resistência ao ataque de S. zeamais, concluíram que as maiores médias de perda de peso estão relacionadas à menor resistência que os grãos apresentam ao ataque dos insetos.

Em seu trabalho sobre a influência de diferentes sistemas de adubação na composição nutricional do milho e seus efeitos sobre o ataque de S. zeamais, Massaro Júnior et al. (2007) constataram maior perda de peso dos grãos de milho nos tratamentos em que ocorreu maior número de emergência de insetos.

\section{Análise tecnológica de defeitos}

Os resultados apresentados na análise de defeitos (Tabela 2) variaram entre os três períodos de armazenamento avaliados. A maior média apresentada de grãos carunchados foi ao final dos 120 dias, fato explicado em virtude deste período apresentar o maior número de insetos adultos de $S$. zeamais pelo fato de ter ocorrido a emergência de uma segunda geração em relação à população inicial.

Tabela 2. Médias das anál ises de defeitos gerais de milho híbrido armazenado com população de 150 insetos adultos de $S$. zeamais, em quatro períodos diferentes: 0 , 30,60 e 120 dias

\begin{tabular}{lcccr}
\hline Tipo de dano & \multicolumn{4}{c}{ Período de armazenamento (dias) } \\
\cline { 2 - 5 } do grão (\%) & $\mathbf{0}$ (inicial) & $\mathbf{3 0}$ & $\mathbf{6 0}$ & $\mathbf{1 2 0}$ \\
Carunchado & $0,53 \mathrm{C}$ & $2,37 \mathrm{c}$ & $9,77 \mathrm{~b}$ & $34,01 \mathrm{a}$ \\
Chocho & $0,10 \mathrm{a}$ & $0,33 \mathrm{a}$ & $0,32 \mathrm{a}$ & $0,75 \mathrm{a}$ \\
Quebrado & $3,03 \mathrm{a}$ & $3,28 \mathrm{a}$ & $1,86 \mathrm{a}$ & $3,05 \mathrm{a}$ \\
Ardido & $0,52 \mathrm{~b}$ & $0,37 \mathrm{~b}$ & $0,23 \mathrm{~b}$ & $1,73 \mathrm{a}$ \\
Fragmentado & $3,46 \mathrm{ab}$ & $3,08 \mathrm{~b}$ & $3,03 \mathrm{~b}$ & $5,01 \mathrm{a}$ \\
Fermentado & $0,00 \mathrm{a}$ & $0,00 \mathrm{a}$ & $0,00 \mathrm{a}$ & $0,00 \mathrm{a}$ \\
Germinado & $0,18 \mathrm{a}$ & $0,00 \mathrm{a}$ & $0,00 \mathrm{a}$ & $0,00 \mathrm{a}$ \\
Mofado & $0,00 \mathrm{a}$ & $0,00 \mathrm{a}$ & $0,00 \mathrm{a}$ & $0,00 \mathrm{a}$ \\
Impurezas & $0,42 \mathrm{a}$ & $0,00 \mathrm{a}$ & $0,00 \mathrm{a}$ & $0,24 \mathrm{a}$ \\
Inteiro & $91,76 \mathrm{a}$ & $90,57 \mathrm{a}$ & $84,79 \mathrm{~b}$ & $55,21 \mathrm{C}$ \\
\hline Médias seguidas de mesma letra na linha não diferem estatisticamente pelo teste de Tukey a 1\%
\end{tabular}

Esses resultados mostram, ainda, diferenças estatísticas entre 30, 60 e 120 dias, não ocorrendo diferenças entre o tempo inicial e 30 dias e que, após 120 dias, a quantidade de grãos carunchados foi 33,48\% superior em relação à inicial.

Em contrapartida, o número de grãos inteiros diminuiu ao longo do armazenamento variando significativamente entre 30 , 60 e 120 dias, visto que o aumento de grãos carunchados leva a uma redução dos grãos inteiros.

As médias de grãos ardidos e fragmentados só apresentaram diferenças ao final do período de armazenamento, ao contrário dos demais resultados, que não apresentaram diferenças estatísticas.

Ao se realizar a classificação desses lotes através da análise tecnológica de defeitos conclui-se que, aos 120 dias, os grãos estariam abaixo do nível padrão para comercialização, aderindo prejuízos para o produtor. Aos 60 dias, este lote seria classificado como tipo 2, devido ao percentual de grãos danificados ser superior a $11 \%$ e inferior a $18 \%$. Já os lotes inicial e 30 dias, seriam classificados como tipo 1 (Brasil, 1996), demonstrando que o ataque de insetos leva à desvalorização comercial do produto.

\section{Resíduo produzido e população de insetos}

A produção de resíduo foi superior ao final do período de 120 dias de armazenamento, devido ao maior número de insetos presentes neste período. Comparando-se as médias, não ocorreu diferença significativa, somente entre 30 e 60 dias. Não foram encontrados, na literatura, trabalhos citando o resíduo produzido.

Como muitos insetos secundários vivem associados aos primários, esses resíduos facilitariam sua permanência nos lotes e assim danos maiores seriam causados, diminuindo a qualidade físico-química dos grãos armazenados. Os prejuízos seriam ainda maiores no momento da comercialização.

Na comparação das médias de sobrevivência, mortalidade e emergência, o armazenamento de 120 dias apresentou os maiores valores diferindo estatisticamente de 30 dias em todas as 
categorias analisadas e não diferiu estatisticamente de 60 dias, isto somente na média de sobrevivência; já 30 e 60 dias não apresentou diferença estatística na média relativa à mortalidade (Tabela 3).

Tabela 3. Médias de resíduo produzido, variação populacional ( $n^{\circ}$ de insetos) e da umidade dos grãos de milho híbrido devido à presença de $\mathrm{S}$. zeamais em três períodos diferentes: 30,60 e 120 dias

\begin{tabular}{lcrrr}
\hline & \multicolumn{4}{c}{ Período de armazenamento (dias) } \\
\cline { 2 - 5 } & $\mathbf{0}$ (inicial) & \multicolumn{1}{c}{$\mathbf{3 0}$} & $\mathbf{6 0}$ & \multicolumn{1}{c}{$\mathbf{1 2 0}$} \\
Resíduo (g) & --- & $2,68 \mathrm{~b}$ & $4,56 \mathrm{~b}$ & $13,49 \mathrm{a}$ \\
Sobrevivência & -- & $114,25 \mathrm{~b}$ & $441,25 \mathrm{a}$ & $537,25 \mathrm{a}$ \\
Emergência & --- & $7,50 \mathrm{C}$ & $345,25 \mathrm{~b}$ & $442,00 \mathrm{a}$ \\
Mortalidade & -- & $13,25 \mathrm{~b}$ & $54,00 \mathrm{~b}$ & $829,25 \mathrm{a}$ \\
Umidade (\%) & $11,34 \mathrm{a}$ & $11,50 \mathrm{a}$ & $11,97 \mathrm{a}$ & $12,55 \mathrm{a}$ \\
\hline
\end{tabular}

Médias seguidas de mesma letra na linha não diferem estatisticamente pelo teste de Tukey a $1 \%$

Em relação ao número final de insetos neste experimento, obtiveram-se 630, 1981 e 3917 insetos para 30, 60 e 120 dias, respectivamente.

Massaro Júnior et al. (2008) obtiveram, ao estudar a resistência de grãos de milho híbrido ao ataque de S. zeamais, um aumento significativo na população de insetos durante 30 dias de armazenamento.

Esses autores utilizaram 11 híbridos diferentes infestados com 15 fêmeas e cinco machos de $S$. zeamais cada um. Os híbridos mais resistentes apresentaram os menores valores de emergência, porém os mais suscetíveis apresentaram mais de 100 insetos emergidos.

Caneppele et al. (2003), avaliando o aumento da infestação de 50 insetos da espécie $S$. zeamais em grãos de milho armazenados por 120 dias observaram, ao final deste período, uma infestação de 899 insetos.

Já Silva et al. (2006), ao realizarem um modelo analítico de crescimento populacional de $S$. zeamais em trigo armazenado com diferentes infestações e temperaturas, constataram que o crescimento populacional aumenta conforme a quantidade inicial de insetos que infestaram cada parcela, sendo a temperatura ideal de $28^{\circ} \mathrm{C}$ com drásticas diminuições abaixo e acima desta.

Com 90 dias de infestação na temperatura de $28{ }^{\circ} \mathrm{C}$, esses autores obtiveram $2.430,8$ insetos por quilograma de trigo para uma população inicial de 1,3 insetos por quilograma; já a maior população inicial (9,3 insetos por quilograma) atingiu 9.603,4 insetos por quilograma.

\section{Análise de umidade}

A umidade em base úmida dos grãos, não diferiu estatisticamente ao longo do tempo de armazenamento (Tabela 3), resultado que está de acordo com Silva et al. (2003) que analisaram as perdas causadas por S. zeamais e Rhyzopertha Dominica (Fabricius) (Coleoptera: Bostrichidae) em trigo armazenado.

Segundo esses autores, a umidade dos grãos aumentou conforme também aumentou a população de ambos os insetos presentes no armazenamento. Os autores ainda relatam que, em seu modelo utilizado no trabalho, resultaria um aumento de umidade de 3,6 pontos percentuais em 90 dias de armazenamento para uma população de 7333 insetos por kg de grãos.

De acordo com Pinto et al. (2002) este aumento do teor de umidade se deve ao metabolismo dos insetos, ou seja, devido à sua respiração (Flinn \& Hagstrum, 1990; Hagstrum \& Flinn, 1990).

\section{Teor de gordura, proteína e peso de 1000 grãos}

As médias do teor de gordura diminuíram ao longo do armazenamento mostrando diferenças significativas entre $0 \mathrm{e}$ 30 dias e 60 e 120 dias, e uma redução de $42,55 \%$ da gordura, ao final dos 120 dias de armazenamento, em relação ao valor inicial $(7,05 \%)$.

Tal diminuição da gordura acarreta problemas para a fabricação de rações, pois a gordura é um dos constituintes mensurados na elaboração da dieta voltada para o ganho de peso de animais de cortes comerciais. Ao comercializar este lote ou fabricar a própria ração, o produtor não terá os ganhos esperados podendo arcar, até mesmo, com prejuízos aos custos de fabricação/implementação da lavoura.

Puzzi (1986), constatou que, praticamente, os insetos se alimentam de endosperma na fase larval e depois, na fase adulta, do gérmen, o que causa considerável perda de peso e do poder germinativo das sementes. O consumo do gérmen acarreta em alterações nutricionais do grão (Lopes et al., 1988).

Segundo Kent (1983), o endosperma contém aproximadamente $74 \%$ da proteína e $15,4 \%$ dos lipídeos e o gérmen contém aproximadamente $26 \%$ da proteína e $83 \%$ dos lipídios.

Segundo Matioli \& Almeida (1979) os insetos atacam primeiro o endosperma do grão de milho, porém os insetos consomem mais o germe, causando uma diminuição maior na gordura e a proteína pode até aumentar, por duas razões: primeiro, por proporção normal devido ao consumo maior de gordura e menor de proteína e, segundo, porque na amostra pode ser determinada, juntamente com a proteína dos grãos, a proteína dos insetos e, com isto, pode também aumentar a percentagem.

Os resultados de proteína não apresentaram variações significativas ao longo do tempo de armazenamento, mostrando que o teor de gordura é um dos constituintes químicos mais deteriorados pelos insetos.

Os resultados de peso de 1000 grãos foram menores ao final dos 120 dias. Ocorreram diferenças estatísticas significativas do valor inicial com os três períodos de armazenamento para o peso de 1000 grãos.

A perda final foi superior a $13 \%$ em relação ao peso inicial, o que se deve ao fato de, com o passar do tempo de armazenamento, maior foi a quantidade de insetos presentes em cada período, assim como os danos causados por esses insetos, levando à redução do peso desses grãos (Tabela 4). Não foram encontrados, na literatura, trabalhos citando peso de 1000 grãos. 
Tabela 4. M édias de teor de gordura, proteína e peso de 1000 grãos de grãos de milho híbrido devido à presença de S. zeamais em três períodos diferentes: 30, 60 e 120 dias

\begin{tabular}{lrrrr}
\hline & \multicolumn{4}{c}{ Período de armazenamento (dias) } \\
\cline { 2 - 5 } & $\mathbf{0}$ (inicial) & $\mathbf{3 0}$ & $\mathbf{6 0}$ & \multicolumn{1}{c}{$\mathbf{1 2 0}$} \\
Proteína (\%) & $9,11 \mathrm{a}$ & $9,12 \mathrm{a}$ & $9,60 \mathrm{a}$ & $10,20 \mathrm{a}$ \\
Gordura (\%) & $7,05 \mathrm{a}$ & $5,68 \mathrm{~b}$ & $5,12 \mathrm{~b}$ & $4,05 \mathrm{C}$ \\
Peso de 1000 grãos (g) & $321,64 \mathrm{a}$ & $300,90 \mathrm{ab}$ & $291,38 \mathrm{~b}$ & $280,07 \mathrm{~b}$ \\
\hline
\end{tabular}

Médias seguidas de mesma letra na linha não diferem estatisticamente pelo teste de Tukey a $1 \%$ * Os valores de proteína e gordura estão em base seca

\section{Conclusões}

1. Com o aumento do período de armazenamento dos grãos de milho híbrido na presença de $S$. zeamais, maiores serão as perdas de peso sofridas pelos grãos.

2. Quanto maior a população dos insetos presentes na armazenagem maior o resíduo produzido.

3. A gordura teve redução superior a $40 \%$, o constituinte químico que mais diminui durante o armazenamento.

4. A quantidade de grãos danificados, principalmente os carunchados, aumenta conforme o tempo de armazenamento e a população de insetos presentes, levando a uma desvalorização comercial do produto.

5. Quanto maior o tempo de exposição dos grãos de milho aos insetos maior será, também, a população final.

\section{LITERATURA CITADA}

AACC - American Association of Cereal Chemists. Approved methods AACC, 10th ed. St. Paul: AACC, 2000.

Anderson, K.; Schurle, B.; Reed, C.; Pedersen, J. An economic analysis of producers decisions regarding insect control in stored grain. North Central Journal of Agricultural Economics, v.12, p.23-29, 1990.

AOCS - Official and Tentatives Methods of American Oil Chemestry Society, New York: AOCS, 1996.

Bakker-Arkena, F. W. Grain quality and management of grain quality standards. In: International Symposium of Grain Conservation, 1994, Canela. Anais... Porto Alegre: Plus Comunicações, 1994. p.3-11.

Braga, L. G. T.; Lopes, D. C.; Costa, N. M. B.; Pereira, J. S.; Teixeira, M. P. Uso de rato de laboratório para determinar o valor nutritivo do milho em diversos níveis de carunchamento. Revista Brasileira de Zootecnia, v.32, p.331336, 2003.

Brasil. Ministério da Agricultura e Reforma Agrária. Portaria n. 11, de 12 de abril de 1996. Comissão Técnica de Normas e Padrões. Norma de identidade, qualidade, embalagem e apresentação do milho. Brasília: MAPA, 1996. 2p.

Brasil. Ministério da Agricultura e Reforma Agrária. Secretaria Nacional de Defesa Agropecuária. Departamento Nacional de Defesa Vegetal. Coordenação de Laboratório Vegetal. Regras para análise de sementes. Brasília: MAPA - SDA CGAL, 2009. 398p.
Canepelle, M. A. B; Caneppele, C.; Lázzari, F. A.; Lázzari, S. M. N. Correlation between the infestation level of Sitophilus zeamais Motschulsky, 1855 (Coleoptera, Curculionidae) and the quality factors of stored corn, Zea mays L. (Poaceae). Revista Brasileira de Entomologia, v.47, p.625-630, 2003.

Faroni, L. R. D. A. Manejo das pragas dos grãos armazenados e sua influência na qualidade do produto final. Revista Brasileira de Armazenamento, v.17, p.36-43, 1992.

Flinn, P. W.; Hagstrum, D. W. Simulations comparing the effectiveness of various stored-grain management practices used to control the lesser grain borer, Rhyzopertha dominica (F.) (Coleoptera: Bostrichidae). Environmental Entomology, v.19, p.725-729, 1990.

Hagstrum, D. W.; Flinn, P. W. Simulations comparing insect species differences in response to wheat storage conditions and management practice. Journal of Economic Entomology, v.83, p.2469-2475, 1990.

Kent, N. L. Tecnology of cereal 3.ed. Oxford: Pergamon Press, 1983. 221p.

Lopes, D. C.; Fontes, R. A.; Donzele, J. L. Perda de peso e mudanças na composição química do milho (Zea mays, L.) devido ao carunchamento. Revista da Sociedade Brasileira de Zootecnia, v.17, p.367-371, 1988.

Massaro Júnior, A. L.; Lazzari, S. M. N.; Figueira, E.L. Z.; Hirooka, E. Y. Inibidores de amilase em híbridos de milho como fator de resistência a sitophilus zeamais (Coleoptera: Curculionidae). Revista Neotropical Entomology, v.34, p.443-450, 2005.

Massaro Júnior, A. L.; Lazzari, S. M. N.; Souza, J. L.; Lazzari, F. A; Cândido, L. M. B. Influência de diferentes sistemas de adubação na composição nutricional do milho Zea mays $\mathrm{L}$. (Poaceae) e seus efeitos no ataque de Sitophilus zeamais Motschulsky (Coleoptera: Curculionidae) no produto armazenado. Semina: Ciências Agrárias, v.28, p.51-64, 2007.

Massaro Júnior, A. L.; Vilarinho, A. A.; Paiva, W. R. S. C.; Barreto, H. C. S. Resistência de híbridos de milho ao ataque de Sitophilus zeamais Motschulsky (Coleoptera: Curculionidae) em condições de armazenamento. Revista Acadêmica, Ciências Agrárias e Ambientais, v.6, p.45-50, 2008.

Matioli, J. C.; Almeida, A. A. Alterações nas características químicas dos grãos de milho causadas pela infestação do Sitophilus oryzae. Revista Brasileira de Armazenamento, v.4, p.36-46, 1979.

Pinto, U. M.; Faroni, L. R. D. A.; Alves, W. M.; Silva, A. A. L. Influência da densidade populacional de Sitophilus zeamais (Motsch.) sobre a qualidade do trigo destinado à panificação. Acta Scientiarum, v.24, p.1407-1412, 2002.

Puzzi, D. Abastecimento e armazenamento de grãos. São Paulo: Instituto Campineiro de Ensino Agrícola, 1986. 1917p.

Santos, A. K.; Faroni, L. R. D. A.; Guedes R. N. C.; Santos, J. P.; Rozazdo, A. F. Nível de dano econômico de Sitophilus zeamais (M.) em trigo armazenado. Revista Brasileira de Engenharia Agrícola e Ambiental, v.6, p.273-279, 2002.

Schöller, M.; Prosell, S.; Al-Kirshi, A. G.; Reichmuth, C. H. Towards biological control as a major component of integrated pest management in stored product protection. Journal of Stored Products Research, v.33, p.81-97, 1997. 
Silva, A. A. L.; Faroni, L. R. D. A.; Guedes, R. N. C.; Martins, J. H.; Pimentel, M. A. G. Modelagem das perdas causadas por Sitophilus zeamais e Rhyzopertha dominica em trigo armazenado. Revista Brasileira de Engenharia Agrícola e Ambiental, v.7, p.292-296, 2003.

Silva, A. A. L.; Faroni, L. R. D. A.; Guedes, R. N. C.; Martins, J. H.; Pimentel,M. A. G. Modelos analíticos do crescimento populacional de Sitophilus zeamais em trigo armazenado. Revista Brasileira de Engenharia Agrícola e Ambiental, v.10, p.155-161, 2006.
Silva, J. S.; Afonso, A. D. L.; Guimarães, A. C. Estudos dos métodos de secagem. In: Silva, J. S. Pré-processamento de produtos agrícolas. Juiz de Fora: Instituto Maria 1995. p.105143.

Silveira, R. D.; Faroni, L. R. D. A.; Pimental, M. A. G.; Zocolo, G. J. Influência da temperatura do grão de milho, no momento da pulverização, e do período de armazenamento, na mortalidade de Sitophilus zeamais e Tribolium castaneum, pela mistura bifenthrin e pirimifós-metil. Revista Brasileira de Armazenamento, v.31, p.120-124, 2006. 